CCC 2019

Proceedings of the Creative Construction Conference (2019) 104

Edited by: Miroslaw J. Skibniewski \& Miklos Hajdu

https://doi.org/10.3311/CCC2019-104

Creative Construction Conference 2019, CCC 2019, 29 June - 2 July 2019, Budapest, Hungary

\title{
A Study on a Conceptual Data Model for Developing a Building Fire Information Management System
}

\author{
SuHyun Jung ${ }^{\mathrm{a}}$, HeeSung Cha ${ }^{\mathrm{a}, *}$ \\ ${ }^{a}$ Department of Architecture Engineering, Ajou university, Suwon 16499, South Korea
}

\begin{abstract}
Recently, as large-scale indoor fires have increased, fire-response systems that enable systematic and effective responses have become more important. Despite the need for the quick and intuitive gathering of relevant information for effective fire response, current information transmission systems are based on paper documents and the opinions of the people nearby. These actions can delay the response time and often cause inappropriate judgments. For an effective fire response in a building, it is important to quickly and intuitively collect and provide relevant information such as location data, available fire equipment, and risk factors in the event of a fire. Building Information Modeling (BIM) can be used in various ways from 3D visualization to spatial data management. Despite these advantages, utilizing data stored in BIM remains a challenge for emergency responders who respond directly at fire sites. This study aims to propose information requirements and conceptual data structure for the development of BIM based building fire information management system for fire response. This can store management history data and build a database so that the required information can be delivered quickly in case of a fire. Based on this paper, the proposed building data structure is expected to design a data model for the construction of the fire related information system database in the field of building disaster management. In future research, a system prototype will be developed with this conceptual model and its effectiveness will be verified by applying it in actual practice.
\end{abstract}

(C) 2019 The Authors. Published by Budapest University of Technology and Economics \& Diamond Congress Ltd.

Peer-review under responsibility of the scientific committee of the Creative Construction Conference 2019.

Keywords: Fire responase; Data model; Data management; Building Infomration Modeling (BIM)

\section{Introduction}

Building fires are difficult to predict and thus suggest the importance of managing and inspecting relevant information about facilities in buildings. Serious damage in building fires are caused by insufficient safety management and inspection systems, inoperative fire facilities in a building, or insufficient fire response manuals and behavior [1]. The issue of how to support and cope with a fire site quickly and accurately plays an important role in the early fire response. Therefore, emergency responders such as facility managers and rescue teams should be aware of the correct situation to make optimal decisions and should be able to analyze fire situations using all the information generated at the fire site [2]. Although they need to quickly and intuitively collect relevant information from the fire site, the current

*Corresponding author email: hscha@ajou.ac.kr 
SuHyun Jung, et al. / Proceedings of the Creative Construction Conference (2019) 104 https://doi.org/10.3311/CCC2019-104

information system is based on paper documents and listening to the opinions of nearby people. These actions can delay the response time and often cause inappropriate judgment [3]. When a fire deteriorates, it is also important for the rescue team to utilize the fire facilities installed in the building, but such information is often unavailable and the utilization rate is poor [4]. Briefly, indoor spatial information including available fire facilities should be provided to rescue teams for effective building fire response [5]. Consequently, facility managers should store and manage such information in advance and transmit it immediately to the rescue team in a fire response.

Building disaster management, particularly for fires, must be managed through a consistent and systematic management system that goes beyond meeting the minimum safety requirements under existing law so that the latest building information can be provided to users immediately in a fire response. Building and indoor facilities information visualized in 3D can be intuitively understood in emergency situations [6]. Systematic information management can also improve the reliability of information. Building Information Modeling (BIM) is of increasing interest in consistent information management applications as "an approach to the digital representation of design, construction and facility management processes to facilitate data exchange and interoperability [7]" in the architecture, engineering, and construction industries. As the advantages of BIM application have been proved in each field of the AEC industry, the potential benefits of BIM are being discussed in fire safety and disaster management as it allows emergency responders to share location data and key information of critical elements in fire response in connection with information generated during the building operation and maintenance phase [6,7]. Despite these advantages, BIM in the field of building fire safety and response remains poorly utilized as an information management tool, which means that object and attribute data goes under-utilized, which is the biggest advantage of BIM.

This study's main purpose is to confirm the information requirements of building fire response before constructing the database for the development of a Building Fire Information Management System (BFIMS). This paper constructs the data structure of information required for emergency responders in building fires to use 3D BIM technology, which can store object and attributes data as building elements. A system framework and development direction is proposed that can apply to the data model presented in this paper. The proposed data structure is derived from several previous published studies and practical data on the basis of building fire management. In addition, the current building fire response method was investigated and its limitations are identified. The information requirements for emergency responders were derived from expert interviews to design a data structure that reflected the information requirements. This was intended to improve the usability of reliable location data and key information of building elements and fire facilities for emergency responders. Consequently, it will likely improve the fire responsiveness of emergency responders in building fires.

\section{Current Building fire response method and limitations}

Disaster management refers to all activities involved in the prevention, preparation, response to, and recovery from disasters in accordance with the sequence of time activities. The response phase is all types of activities that minimize the loss of life and property by prompt action in the event of a disaster. In the building fire response, facility managers and rescue teams play an important role as the main body of action capable of a direct response in the early stages of fire occurrence.

Occupants who are unfamiliar with the building tend to choose routes that are relatively inadequate because they do not recognize evacuation facility information such as emergency exits and emergency stairs [8]. As the building's size increases, it becomes more difficult for them to recognize escape routes easily because the general route and evacuation route are separate. In this situation, the facility manager has a significant impact on occupants' behavior [9]. Facility managers conduct disaster prevention and preparation such as building safety checks, emergency drills, real-time monitoring, and announcement inspections. For example, the facility manager should inspect and record the operation and function of fire-safety related facilities at least once a year depending on the building's size. However, these records typically only document the results of actions against malfunctions, so most of the data is temporary. Therefore, systematic data management is insufficient and it is almost impossible to use related information in a fire response. 
SuHyun Jung, et al. / Proceedings of the Creative Construction Conference (2019) 104 https://doi.org/10.3311/CCC2019-104

The rescue team arrives at the fire site within 5-10 minutes after the fire notification and receipt. During the short dispatch process, they receive the schematic drawings to their mobile devices such as the site commander's desktop PC and grasp the building's approximate size and shape. However, the rescue teams can only receive information on specific buildings as specified by law and most relevant information is collected by the rescue teams about the surrounding data sources (nearby residents, victims, building-related people, fire activity information card, etc.) after arrival at the fire site. Even if they have drawings in advance, changes are not reflected during use, so there may be no link between the actual building and the drawing. In addition, two-dimensional drawings have limited capability to express complex spatial relationships in large-scale buildings [10]. These practices will likely collect inaccurate information at confusing fire sites and making optimal decisions takes too much time [11].

When the rescue team extinguishes the fire inside a building, they have difficulty identifying the internal situation due to flames and smoke and difficulty judging the method of suppression due to their lack of knowledge about the building. In particular, if a fire continues, they have to utilize firefighting facilities installed in the building besides the prepared equipment. However, there is no accurate information about the installation location of facilities, so their utilization is often poor [4]. To maximize the utilization of this information, each fire station conducts a survey on the status of firefighting facilities for specific fire target buildings within the jurisdiction at regular intervals and records a survey of the relevant physical factors that are necessary for firefighting tasks. They conduct data surveys that are necessary for firefighting facilities such as evacuation facilities and hazardous materials facilities. However, since these fire activity information cards are based on paper documents, the location data for each installed facility in a building cannot be identified by the facility manager or confirmed directly at the fire site.

\section{Expert interview on the current system limitations}

Facility managers and fire brigades were interviewed to assess the limitations of the current fire response system. The facility managers explained why the utilization of firefighting facilities installed in buildings is inevitably low for buildings' current fire response systems. Related laws for disaster safety management are increasingly strengthened, but existing buildings use aged facilities that are limited in their application of the latest laws. Furthermore, since such buildings are limited to buildings of a certain size, existing small- and medium-sized buildings are vulnerable to fire. The biggest problems for rescue teams when firefighting in current buildings is the inconsistencies between provided drawings and actual buildings and the absence of location data on fire ignition and related facilities.

To improve the effectiveness of existing fire response systems, rescue teams should be able to identify the latest building information and related location information. To support this, the facility managers should be provided with an information management system that can store information required in fire response in advance and continuously update it [12]. In addition, information should be systematically managed in emergency situations so that reliable information can be immediately transmitted to rescue teams. This is required to secure the quality of each data set for reliable information, and data standardization should be performed to enhance the quality management of information [13]. The absence of data standards hinders effective information flow among emergency responders. Therefore, the management information of the building and facilities that can be used in fire sites should be prepared in advance and data structures are required to organize system database construction.

\section{Data structure for building fire response}

As predicting building fires is difficult, building information management based on location data is required in terms of fire prevention and response. Previous research results on the development of building information management systems are being published. The demand for IT technology is increasing as the role of collecting and analyzing various aspects of data. In addition, the combination of computer technology and fire safety management has become a trend. As described above, information-based decision making is a critical factor at fire sites, but direct access to information to assist rescue teams in situation awareness is vulnerable. In particular, sharing indoor information required for search and rescue is insufficient and lacks objective and quantitative data, which makes decisions difficult [14]. The quality assurance of data collection should be considered in building fire sites because facility managers and rescue teams should be able to communicate accurate and reliable information in minimal time. Therefore, data standardization 
SuHyun Jung, et al. / Proceedings of the Creative Construction Conference (2019) 104 https://doi.org/10.3311/CCC2019-104

should be the first priority and data classification is the most basic problem to be solved for information management. Vimala nunavath et al. [2] what information was required for on-site control during search and rescue on a campus and indicated identified items as a useful tool for communicating with end users using the UML model. Nan Li et al. [3] categorized the information requirements before and after the arrival of a rescue team using the scenario methodology. Through a one-on-one interview with the rescue team, the card game method can be used in which the rescue team becomes a virtual player and derives necessary data according to the response process. Rui et al. [15] presented a data model that could be used in fire response from a business perspective. This data model has established a comprehensive information standard classification system for fire response by accessing activities according to on-site and off-site rescue response processes. Bae and Park [16] derived five management for safety management in the underground space and analyzed the fire risk assessment weights for each detail.

All of the above studies emphasized the necessity of information requirements for facility managers and rescue teams and made efforts to standardize the data structure for what information can be utilized in fire responses. They contributed to the classification of required information according to the user in the fire response. However, as there are overlapping items in a large category of required information between facility managers and rescue teams, additional alternatives to integrated information management are required that can be used either directly or indirectly. In other words, it is somewhat difficult to apply the integrated system in terms of data sharing and data management because the items have been changed according to the method of conducting the research or the users and this is classified without reflecting the linkage of information between emergency responders. As a preliminary step for developing a system database, this paper re-classifies the required information of emergency responders derived from previous studies and reconstructs information that can be provided easily and intuitively in a single-system environment such as BIM according to the response process.

\subsection{Integrated Data structure for emergency responders}

Various data models have been proposed to solve the lack of information in the building fire response. It is necessary to redefine the data structure because the approaches and interpretations differ according to the building type and the end user of information. These proposed information requirements are extracted from the classification proposed by previous studies. Based on the extracted information, they are redefined into items that allow users to maintain a database easily in the system environment to be developed. As depicted in Figure 1, there are 18 items that were mentioned repeatedly in previous studies, including general information about the building, information about the inside of the building, installed facilities and equipment, and real-time fire information. In the building fire response, users' information requirements can be divided into "Pre-gathering data" and "Real-time gathered data." Pre-gathering data is reclassified into five categories, which can be managed in advance: general building information, building space information, fire risk element, available resources in the fire, and maintenance history. Real-time gathered data should be collected and analyzed in real time after a building fire; it is divided into two categories: real-time fire/smoke condition and occupant information. This paper only defines the data structure for the pre-gathering data, which is a data structuring step in which the above information is computerized in advance and utilized as an information support system in the building fire response through continuous data management.

As depicted in Figure 2, it is divided into physical information and management information aspects depending on the data characteristics. In particular, the indoor space element, fire risk element, and available resource element could be managed as a three-dimensional object according to the fire response process during the implementation of BFIMS as proposed in future research. 
SuHyun Jung, et al. / Proceedings of the Creative Construction Conference (2019) 104 https://doi.org/10.3311/CCC2019-104

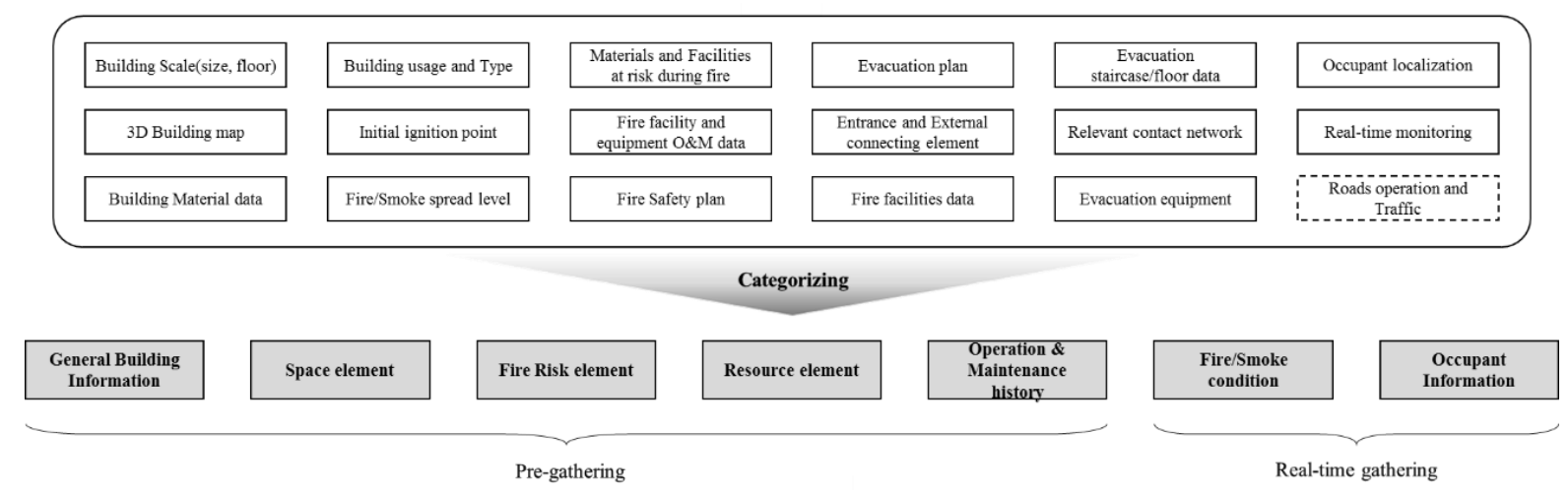

Figure 2. Categorizing data from literature reviews

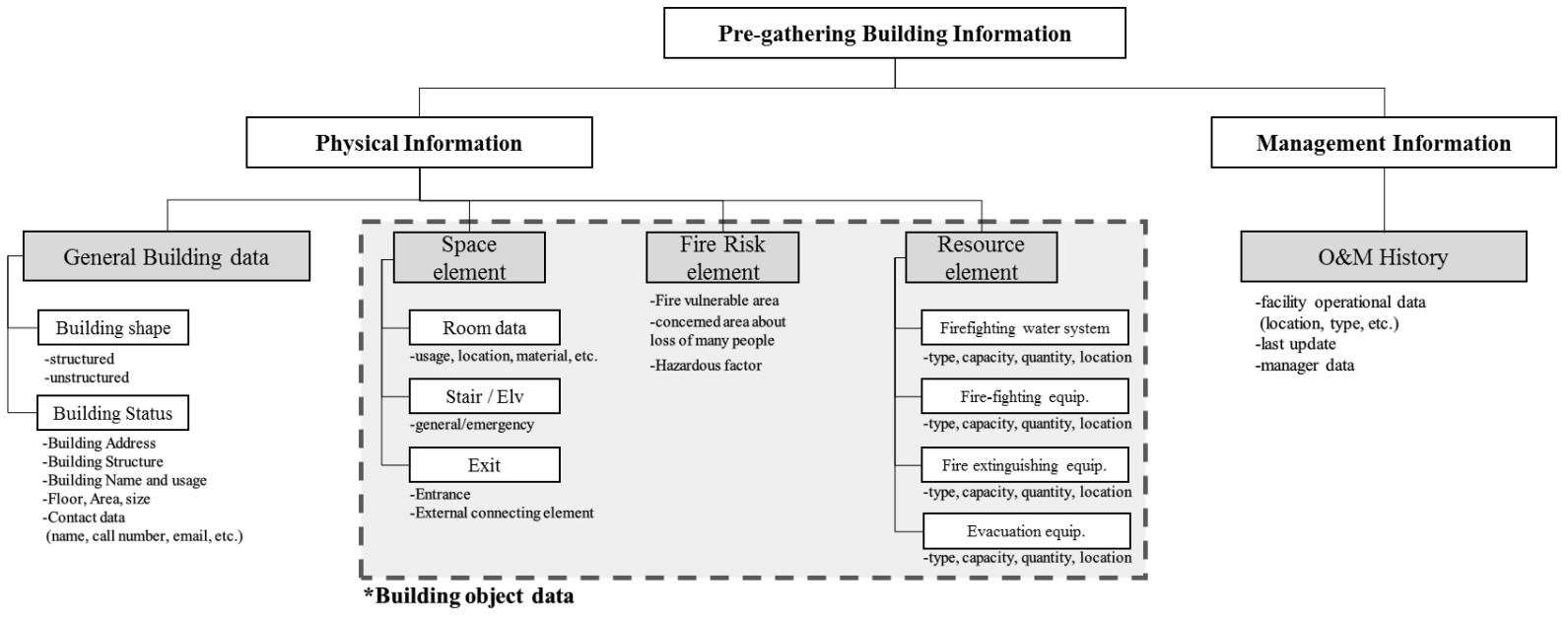

Figure 1. General elements breakdown of Pre-gathering data for building fire response

\section{Conceptual Data model suggestions for System development}

BIMs are a useful tool for storing a vast amount of information and can be used as an integrated information system for indoor spaces. Most of the current BIM studies in the field of building fire-disaster management are used for rescue and evacuation route analysis or fire simulation analysis that take specific factors into account. Wang et al [10] proposed a BIM-based integrated system that consisted of four modules: evacuation analysis and evaluation, evacuation route planning, safety education, and equipment maintenance. The proposed system could analyze fire safety in conjunction with FDS simulation and store information that supports safety management in a web-based environment. Cheng et al [17] conducted a study on an integrated system that could be used continuously in fire prevention and response using BIM and a wireless sensor network. The system displays fire status and occupants' location information on the screen through monitoring and provides two-way route guidance between occupants and rescuers through mobile interlocking and an LED guiding device. Although the above studies have attempted to develop a system with functions such as real-time data acquisition, occupant tracking, and device and equipment management, essential information such as firefighting facilities remains incompletely reflected. Moreover, BIM is used as a platform for visualization, or as a study for convergence with other software. The utilization of spatial information, which is BIM's biggest advantage, is poor. In addition, an integrated management system for fire disaster management is only effective for extracting relevant information rather than operating all BIM information created during a building lifecycle.

This study proposes an integrated classification scheme for information that is commonly required by emergency responders based on the data structure described in Section 3 and defines a user-centric data relationship so that database management is easy based on the derived information requirements. In future studies, a prototype of BFIMS 
SuHyun Jung, et al. / Proceedings of the Creative Construction Conference (2019) 104 https://doi.org/10.3311/CCC2019-104

should be developed using BIM. The first thing to do when designing a system database based on user-required information is defining the DB information requirements (see Table 1). For example, a fire extinguishing facility could be modeled as an object on the system in the resource element of the building object data among the physical information of the pre-gathering data, and the related location, types, and quantities could be expressed in the building modeling. Information requirements could be configured as attribute data according to each class and the relationship between items can be defined.

Table 1. DB Definition of pre-gathering data requirements from data breakdown

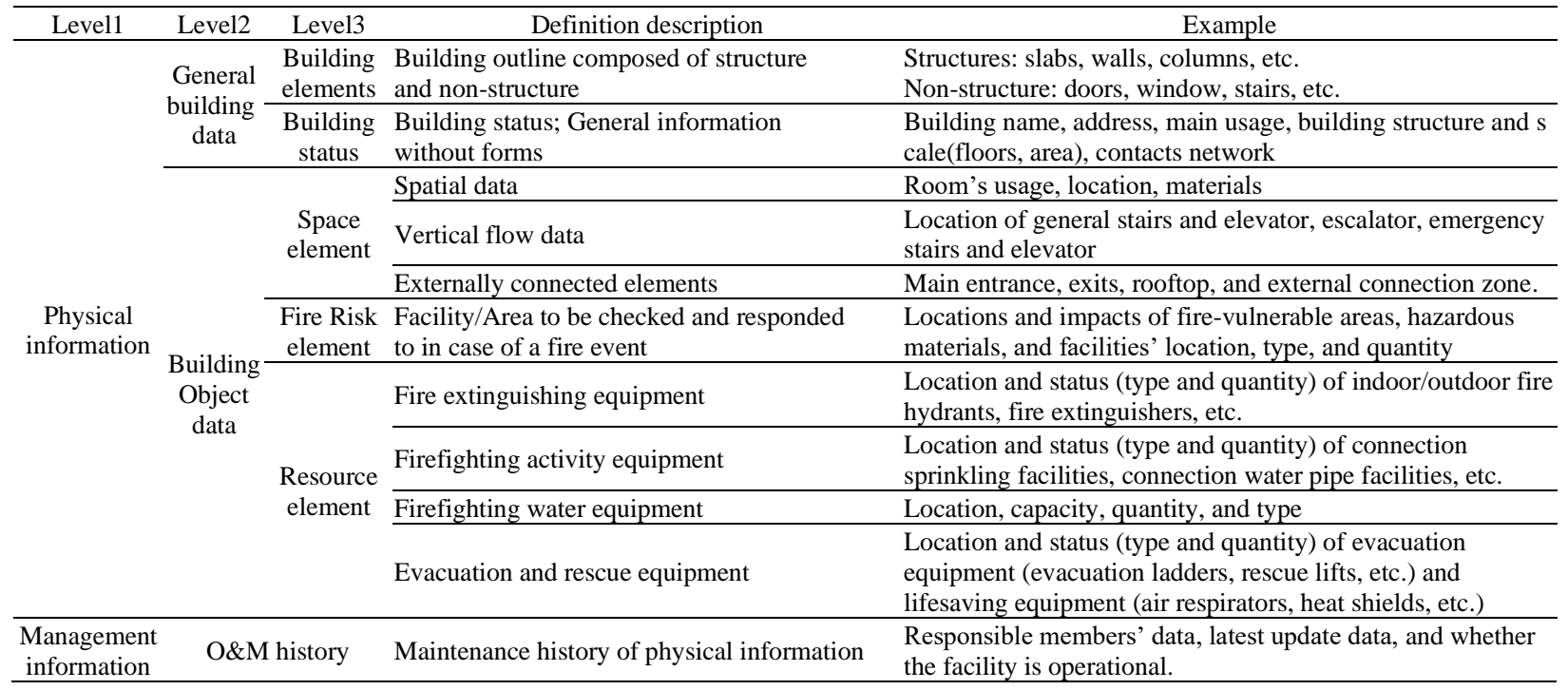

When a data model has been constructed, the platform on which the system will run is selected. The platform determines the system complexity based on plug-ins, user access, and user capability. It should be easy to modify the changes and construct the database. In essence, it is important to set the level of information that can be handled by the user when accessing the system. In general, for facility managers, the system interface and how it works should be simple and easily mastered. In this study, a Sketchup API would be chosen as an alternative. Sketchup is modeling software that has a simple user interface and can configure program add-ons by user's convenience with extensions (called plug-ins). This enables extensions to BIM and 3D modeling. Industry Foundation Classes (IFCs) are an international standard for BIM object libraries developed for data exchange in the AEC industry. Using an IFC model enables interoperability among the various systems that support the IFC format and this can be broadly extended depending on the purpose of development.

In building fire data management, BIM-based systems using IFCs for systematic fire information management systems can design data models that are specialized for fire safety management. A conceptual data model was designed to propose a data structure of BFIMS. This represents the class and data relationship definition. Figure 3 shows the entity relationship focusing on firefighting equipment that is available in building fire response. IfcObject consists of an IfcElement that represents building shape and an IfcSpacitalStructureElement that stores the building general information. The information requirements related building fire response is dependent on IfcInventory class and stores physical and management information. For example, fire hydrant information provides physical information such as type, connection size, and intrinsic characteristics. It includes simple inventory data about simple management information. The information management items to be added according to the user's purpose can be stored and managed in IfcPropertySingleValue. 
SuHyun Jung, et al. / Proceedings of the Creative Construction Conference (2019) 104 https://doi.org/10.3311/CCC2019-104

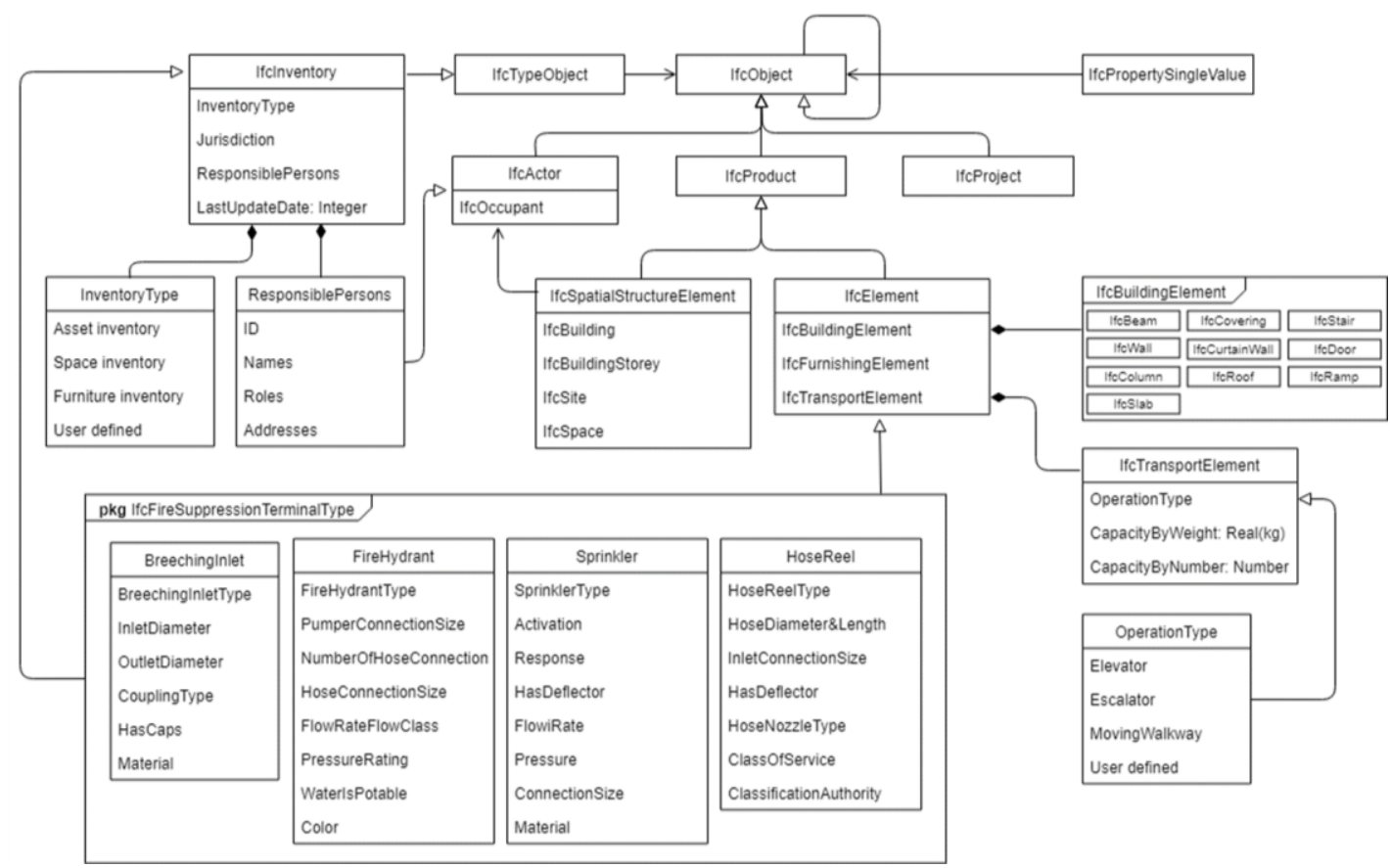

Figure 3. Conceptual IFC data model about predefined Fire Suppression Terminal Type

Figure 4 shows how facility managers and rescue teams can utilize the proposed system in actual situations. Facility managers can acquire detailed information and the inspection history of related fire facilities based on the object data stored in the proposed BFIMS. They also keep their buildings up to date and perform daily monitoring work by reflecting changes when the indoor elements or objects change. When a fire occurs, the system alerts facility managers and provides them with fire-related information such as object's location and attribute data through 3D visualization. Meanwhile, they can grant system access privileges to rescue teams so that they can share information and the rescue team collects relevant information in advance through a shared view when they are dispatched. This supports the establishment of the optimal response strategy by sharing the indoor information that is required in building fires. If BFIMS and intelligent sensors can be combined, it would improve the speed of real-time information collection.

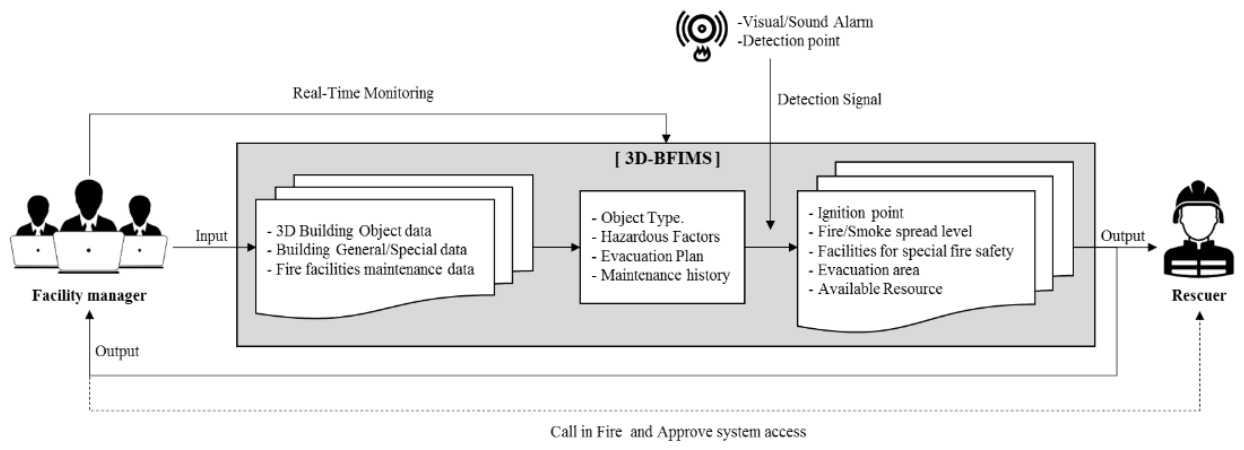

Figure 4. System operation framework

\section{Conclusion}

In coping effectively with building fires, the issue of how to support and respond at a fire site quickly and accurately plays an important role in the early stages of fire occurrence. Emergency responders such as facility managers and rescue teams should be made aware of the correct situation quickly and make optimal decisions using all distributed information that is generated at the fire site. The current building fire response method does not provide rescue teams with the latest information about the building, so the accuracy is low and collecting the required information takes time. Previous studies have sought to obtain the information required for emergency responders and to ensure the 
SuHyun Jung, et al. / Proceedings of the Creative Construction Conference (2019) 104 https://doi.org/10.3311/CCC2019-104

reliability and accuracy of the information gathered during the building fire response using 3D modeling tools such as BIM. However, this is often confined to the technical side and the interpretation can differ depending on the approach.

This paper proposes integrated information requirements for emergency responders by recognizing that appropriate information should be shared among emergency responders in the building fire response. Based on the proposed data structure, a direction was suggested for the development of a 3D building fire information management system (BFIMS). This contributes partly to the field of building fire safety management by suggesting a data structure that includes object-based indoor facility information for effective building fire response. It can also help improve the information usability of the fire response by suggesting a user-centric data structure. It is meaningful that 3D modeling using the proposed data structure can supplement the limitation in the utilization of indoor object information and provide more detailed and intuitive information related to indoor fires. Therefore, it supports the decision making of emergency responders by sharing as much spatial and indoor object information as is required in building fires. Therefore, the initial response speed could be improved, thus contributing practically by improving the building fire responsiveness. In future research, we will develop a system prototype by supplementing the proposed data model and system functions and apply it to actual buildings to verify its effectiveness and efficiency.

\section{Acknowledgements}

This research was supported by the Basic Science Research Program, through the National Research Foundation of Korea(NRF) (NO.2017R1E1A1A01075266).

\section{References}

[1] Jieun Kim, Changhee Hong, A Study on the Application Service of 3D BIM-based Disaster Integrated Information System Management for Effective Disaster Response, Journal of the Korea Academia-Industrial cooperation Society, 19 (2018) 14-150. https://doi.org/10.5762/KAIS.2018.19.10.143

[2] Vimala Nunavath, Andreas Prinz, Tina Comes, Identifying first responders information needs: supporting search and rescue operations for fire emergency response, Int. J. Inf. Syst. Crisis Response Manag.(IJISCRAM) 8(1) (2016) 25-46 https://doi.org/10.4018/IJISCRAM.2016010102

[3] Nan Li, Zheng Yang, Ali Ghahramani, Burcin Becerik-Gerber, Lucio Soibelman, Situational awareness for supporting building fire emergency response: Information needs, information sources, and implementation requirements, Fire Safety Journal, 63 (2014) 17-28. https://doi.org/10.1016/j.firesaf.2013.11.010

[4] Changseop Lee, A Study on the State of Utilizing Fire Facility in Fire Fighting, Journal of the Korean Institute of Fire science and Engineering, 25(2) (2011) 144-148.

[5] Arta Dilo, Sisi Zlatanova, A data model for operational and situational information in emergency response, Applied Geomatics, 3(4) (2011) 207218. https://doi.org/10.1007/s12518-011-0060-2

[6] Burcin Becerik-Gerber, Farrokh Jazizadeh, Nan Li, Gulben Calis, Application areas and Data Requirements for BIM-enabled Facilities Management, J. Constr. Eng. Manage., 138(3) (2012) 431-442. https://doi.org/10.1061/(ASCE)CO.1943-7862.0000433

[7] Shih-Hsu Wang, Wei-Chih Wang, Kun-Chi Wang, Shih-Yu Shih, Applying building information modeling to support fire safety management, Automation in Construction, 59 (2015) 158-167. https://doi.org/10.1016/j.autcon.2015.02.001

[8] T.J. Shields, K.E. Boyce, A Study of Evacuation from Large Retail Stores, Fire Safety, 35 (2000) 25-49. https://doi.org/10.1016/S03797112(00)00013-8

[9] Enrico Ronchi, Daniel Nilsson, Fire evacuation in high-rise buildings: a review of human behavior and modelling research, Fire Science Reviews, 2:7 (2013) 1-21. https://doi.org/10.1186/2193-0414-2-7

[10] Wang, S.H., Wang, W.C., Wang, K.C., Shih, S.Y., Applying building information modeling to support fire safety management, Automation in Construction, 59 (2015) 158-167. https://doi.org/10.1016/j.autcon.2015.02.001

[11] Albert Y. Chen, James C. Chu, TDVRP and BIM Integrated Approach for In-Building Emergency Rescue Routing, J. Comput. Civ. Eng., 30(5) (2016) 1-11. https://doi.org/10.1061/(ASCE)CP.1943-5487.0000522

[12] Myongkue Kim, Jihun Choi, Donmook Choi, A Study on the Effective Maintenance Strategy of the Fire Facilities in Plant, Journal of the Korean Society of Hazard Mitigation, 18 (2018), 173-180. https://doi.org/10.9798/KOSHAM.2018.18.3.173

[13] Hannes Seppanen, H., Kirsi Virrantaus, Shared situational awareness and information quality in disaster management, Safety Science, 77 (2015) 112-122. https://doi.org/10.1016/j.ssci.2015.03.018

[14] Stuart Foltz, Brian Brauer, Communication, Data Sharing, and Collaboration at the Disaster Site, Proceedings of the ASCE International Conference on Computing in Civil Engineering, Mexico, 2005 July 12-15 https://doi.org/10.1061/40794(179)89

[15] Rui Chen, Raj Sharman, H. Raghay Rao, Shambhu J. Upadhyaya, Data Model Development for Fire related Extreme Events: An Activity Theory Approach, MIS Quarterly, 37(1) (2013) 125-147. https://doi.org/10.25300/MISQ/2013/37.1.06

[16] Yoonshin Bae, Jihye Park, Categorizing Safety Management Elements for Fire Preparation and Assessment of Fire Hazard, Journal of the Korean Society of Disaster Information, 7(2) (2011) 96-109.

[17] Cheng, M.Y., Chiu, K.C., Hsieh, Y.M., Yang, I.T., Chou, J.S., Wu, Y.W., BIM integrated smart monitoring technique for building fire prevention and disaster relief, Automation in Construction, 84 (2017), 14-30. https://doi.org/10.1016/j.autcon.2017.08.027 